\title{
Model-based explorations to assess climate risk to summer crop production and its effects on wheat yield in the central wheatbelt of Western Australia
}

\author{
C. Chen ${ }^{\mathrm{a}}$, M. McNee , R. Lawes ${ }^{\mathrm{a}}$ and A. Fletcher \\ ${ }^{a}$ CSIRO Agriculture Flagship, Private Bag 5, PO Wembley WA 6913, Australia \\ ${ }^{b}$ Western Australian No-tillage Farmers Association (WANTFA)
}

Email:chao.chen@csiro.au

\begin{abstract}
Traditionally, summer crops are not grown in the farming systems of central Western Australia (WA) as summer rainfall is infrequent in this Mediterranean-type climate, and crops may not survive or yield poorly. However, summer rainfall has increased in the past few decades, and there have been some interests in growing crops over summer for grain or livestock production. Before integrating them into the farming system, it is important to understand the risk and potential benefit of summer cropping. Agricultural system models such as APSIM can quantify such production possibilities and risks via simulation analyses.
\end{abstract}

In this study, APSIM and long-term (1955-2014) weather data were used to investigate the biomass and grain yield of millet (Panicum milliaceum) and cowpea (Vigna unguiculata) and the potential effects of growing these crops on the yield of the following winter wheat crops near Northam in central wheatbelt of WA, where an average of $21 \%$ of the $421 \mathrm{~mm}$ annual rainfall (1955-2014) fell in the summer period (November-April). The APSIM model, which has been evaluated extensively against field measurements in various other studies, was tested again to gain further confidence in using it for these investigations, by using data from a one-year summer crop (fallow, millet or cowpea)-winter wheat cropping system experiment.

The model predicted biomass of summer crops and yield of following winter wheat well. The observed biomass was $0.22 \mathrm{t} \mathrm{ha}^{-1}$ for millet and $0.31 \mathrm{tha}^{-1}$ for cowpea, and the corresponding simulated values were 0.24 and $0.32 \mathrm{t} \mathrm{ha}^{-1}$, respectively. Long-term simulations showed that summer millet produced $0.85 \mathrm{t} \mathrm{ha}^{-1} \mathrm{of}$ biomass and $0.07 \mathrm{t} \mathrm{ha}^{-1}$ of grain yield on average. In $20 \%$ of seasons, when it rained, millet produced $1.33-2.00 \mathrm{t} \mathrm{ha}^{-1}$ of biomass, with $0.14-0.36 \mathrm{t} \mathrm{ha}^{-1}$ of grain yield. On average, cowpea produced $0.96 \mathrm{t} \mathrm{ha}^{-1}$ of biomass and $0.20 \mathrm{t} \mathrm{ha}^{-1}$ of grain. In $20 \%$ of seasons cowpea produced $1.55-2.89 \mathrm{t} \mathrm{ha}^{-1}$ of biomass and $0.40-0.83 \mathrm{t} \mathrm{ha}^{-1}$ of yield. Summer millet crops slightly reduced winter wheat yields $(3-4 \%)$. By comparison wheat yield grown after summer cowpea was increased by $9-16 \%$, as cowpea increased the reserves of soil mineral nitrogen.

The simulation results suggest that summer cowpea cropping could add value to the farming system and replace summer fallows, however the system needs further evaluation. This analysis also illustrates the power of modelling approach in exploring and understanding plant physiology in cropping systems.

Keywords: APSIM, millet, cowpea, wheat, water balance 


\section{INTRODUCTION}

Traditionally, crops grown during the summer fallow are not part of cropping rotations in central Western Australia (WA), instead farmers retain stubble and maintain a summer fallow prior to the next winter crop. Summer rainfall in this Mediterranean-type climate is low and highly variable. Consequently, summer crop production in central WA is risky, with limited planting.

In the last few decades, a notable increase in summer rainfall in WA has been observed, along with a matching decline in winter rainfall (Asseng and Pannell, 2013). This has recently resulted in some interest in growing crops over summer for grain or livestock production in this climatic region. Summer crops might alter the nutrient and soil water status to the benefit or detriment of winter crop production (Robertson et al., 2005; Wang et al., 2008). A detailed understanding of the risks and potential benefits of summer cropping to achieve out-of-season grain and livestock production and the potential effects of growing summer crops on the following winter wheat can provide useful insights for the development of more sustainable agricultural systems.

Here we explore the value of summer cropping in a Western Australian environment using the APSIM crop simulation model (Holzworth et al. 2014). In this study, the production and variability of summer crops, millet (Panicum milliaceum) and cowpea (Vignaunguiculata) are quantified along with the associated impact on soil water, nutrient cycling and winter crop (wheat) yield using the APSIM model. The model outputs were tested against one year's data from a summer crop (fallow, millet or cowpea) - winter wheat cropping system experiment, followed by a long-term simulation using historical weather data (1955-2014) for Northam in central wheatbelt of WA.

\section{MATERIALS AND METHODS}

\subsection{Site specification}

The study site was Cunderdin, which is located in the middle of the WA wheatbelt (31.6S, 116.9E). Daily historical climate data from 1955 to 2014 were obtained from the patched point data set of SILO (Jeffrey et al., 2001). Rainfall is highly variable both inter- and intra-annually. Annual rainfall ranged from 208 to 703 $\mathrm{mm}$ with a mean of $421 \mathrm{~mm}$ (1955-2014). On average, summer (Nov-Apr) rainfall only accounted for $21 \%$ of total annual rainfall.

Millet and cowpea were selected as representative summer crops and wheat was used as the winter crop. Their maximum rooting depth in this soil was assumed to be $1.5 \mathrm{~m}$ (Asseng et al., 1998).

\subsection{The agricultural system model}

The agricultural production systems simulator APSIM 7.6 (Holzworth et al., 2014) was used to simulate the performance of fallow-wheat, millet-wheat and cowpea-wheat cropping systems. APSIM is a componentbased simulation framework with modules for simulating crop growth and development, soil water and nitrogen dynamics. The model has been well tested, widely used in Australia (Holzworth et al., 2014) and applied in different crop growing zones worldwide (Asseng et al., 2000). APSIM modules used in this study included Wheat, Millet, Cowpea SoilWat, SoilN, SurfaceOM and Manager. Detailed descriptions of APSIM structure, its crop and soil modules can be found in Holzworth et al. (2014) or at the APSIM website: http://www.apsim.info/.

\subsection{Experimental data and model testing}

Observed data on flowering date, biomass, grain yield of summer crops and growth and yield of subsequent winter wheat were used to further test the APSIM model. These data included one year of data (2013-2014) measured in a replicated and randomised experiment at Meenaar, $18 \mathrm{~km}$ east of Northam. The soil at the experiment site is loamy sand, one of the dominant soil types in WA. The hydraulic properties of the soil used in the simulation was obtained from Asseng et al. (1998). In order to investigate the production risk of summer crops and their effects on the following winter wheat, four cropping systems conducted during the experimental period were used to test the model: 
- Summer fallow-wheat (SFW) - In this cropping system, wheat (cv. Corack) was sown on 9 Jun 2014 and harvested after its physiological maturity. At sowing $11 \mathrm{~kg} \mathrm{~N} \mathrm{ha}^{-1}$ was applied as compound fertiliser, and an extra $46 \mathrm{~kg} \mathrm{~N} \mathrm{ha}^{-1}$ was applied during crop growth.

- Millet forage-wheat (MFW) - In this cropping system, millet (cv. Wrajpop) was sown on 25 Oct 2013 and cut on $20 \mathrm{Feb} 2014$ to determine summer forage performance. Wheat was sown and managed as above.

- Millet-wheat forage (MWF) - In this cropping system, millet was sown on 25 Oct 2013 and harvested after maturity. Wheat was sown and fertilized as above, but cut on 17 Sep 2014 to mimic winter wheat forage.

- Cowpea-wheat (CW) - In this cropping system, cowpea (cv. Red caloona) was sown on 25 Oct 2013 and harvested after maturity. Wheat was sown and managed as above.

\subsection{Modelling the production risk of summer crops and the corresponding effects on wheat yield from 1955 to 2014}

The tested APSIM model was used to simulate the crop growth and grain yield of a wheat-summer fallow (crops) cropping system using the historical climate data from 1953 to 2014. The first two years of simulation outputs were discarded to minimise the impacts that result from arbitrary initialisation assumptions. Profiles of soil water content were initialised at the wheat crop lower limit on 1 Jan 1953. The cropping systems of SFW, MFW and CW conducted in the field experiment were simulated to explore the long-term production risk of summer crops and their effects on the following wheat, with another two cropping systems added, i.e. millet-wheat (MW) and cowpea forage-wheat (CFW). In each system, a summer crop (millet or cowpea) was sown depending upon the occurrence of rainfall, with a sowing window from 15 Nov (a time when wheat was physiologically mature in most years) to $31 \mathrm{Jan}$. There were limited sowing opportunities when sowing criteria of more than $15 \mathrm{~mm}$ over 10-day period was used (Table 1). Therefore in this study the sowing criteria for the summer crop was considered as more than $10 \mathrm{~mm}$ of cumulative rainfall was received over a 10-day period to explore summer crop production potential. Wheat was sown between 1 May and 30 Jun if accumulated rainfall was more than $25 \mathrm{~mm}$ over 10 days. All wheat crops were fertilised at a rate of $60 \mathrm{~kg} \mathrm{~N} \mathrm{ha}^{-1}$ as a single application at sowing. A proportion of aboveground residues $(90 \%$ for forage, $70 \%$ of harvested summer crops and $30 \%$ of harvested wheat) was removed to mimic sheep grazing.

Table 1. Percentage of seasons with a sowing opportunity for summer crops (millet and cowpea) using a range of sowing criteria.

Sowing criteria (cumulative rainfall over a 10-day period)

$10 \mathrm{~mm} \quad 15 \mathrm{~mm} \quad 20 \mathrm{~mm} \quad 25 \mathrm{~mm}$

\begin{tabular}{lllll}
\hline Seasons successful to sow (\%) & 59 & 45 & 31 & 25 \\
\hline
\end{tabular}

\section{RESULTS AND DISCUSSIONS}

\subsection{Testing biomass and yield simulations in APSIM}

APSIM simulated biomass for millet and cowpea biomass reasonably well (Fig.1a). Biomass of millet in a MWF system and cowpea in a CW system sowing were 0.22 and $0.31 \mathrm{t} \mathrm{ha}^{-1}$, respectively, and this was simulated well with the value of $0.24 \mathrm{t} \mathrm{ha}^{-1}$ for millet and $0.32 \mathrm{t} \mathrm{ha}^{-1}$ for cowpea (Fig. 1a). The final productivity of wheat, which did not yield significantly differently $(\mathrm{P}=0.5$; The coefficient of variation: 0.02$)$ under different cropping systems, was also simulated well (Fig. 1b), explaining about $85 \%$ of the variation in wheat biomass or yield. The simulations showed that the model was able to simulate biomass production of summer crops and final levels of wheat production. This gives confidence that simulations will respond to different cropping systems in the study area. 

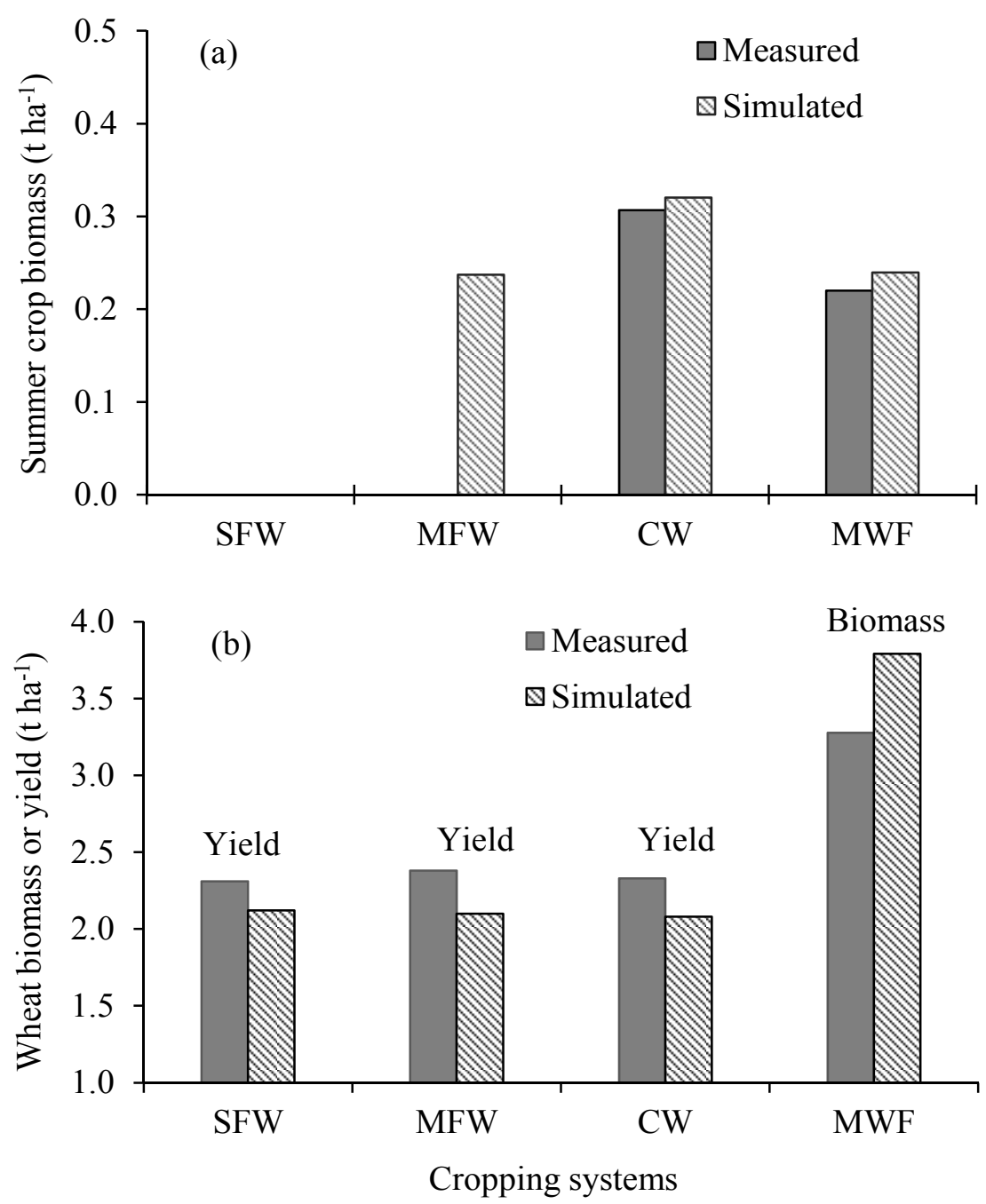

Figure 1. (a) Simulated and measured biomass of summer crops in a millet-wheat forage system (MWF) and cowpea-wheat system (CW); (b) Simulated and measured grain yields of wheat in a summer fallow-wheat system (SFW), millet forage-wheat system (MFW) and cowpea-wheat system (CW). Note: the observed millet biomass in the MFW system was missing.

\subsection{Simulated biomass and yield of summer crops}

The simulations highlighted large inter-annual variation in biomass for both millet and cowpea in all 4 cropping systems (MFW, MW, CFW and CW; Fig. 2). For example, in MW system, simulated millet biomass exceeded $2.00 \mathrm{tha}^{-1}$ in only $2 \%$ of seasons and there was less than $0.1 \mathrm{t} \mathrm{ha}^{-1}$ in about $48 \%$ of seasons (Fig. 2a), with a relatively low average of $0.85 \mathrm{t} \mathrm{ha}^{-1}$ due to the low rainfall during summer in most years. Cowpea, considered as a drought tolerant crop (Halilou et al., 2015), was simulated to produce less than 1.50 $\mathrm{t} \mathrm{ha} \mathrm{a}^{-1}$ biomass of cowpea in about 3 out of 4 seasons with an average of $0.96 \mathrm{t} \mathrm{ha}^{-1}$. In general, few summer crops produced significant grain. Averaged for all seasons, grain yields for millet and cowpea were 0.07 and $0.20 \mathrm{t} \mathrm{ha}^{-1}$, respectively. In $90 \%$ of seasons, grain yields were less than $0.2 \mathrm{t} \mathrm{ha}^{-1}$ for millet and $0.4 \mathrm{t} \mathrm{ha}^{-1}$ for cowpea, and in $75 \%$ of seasons, millet and cowpea yielded less than 0.16 and $0.35 \mathrm{t} \mathrm{ha}^{-1}$, respectively (Fig. 2b). Therefore, summer cropping cannot be relied on to produce economically viable quantities of grain.

The long-term simulations showed that it is highly risky to sow summer crops in this environment due to the low and highly variable summer rainfall. This analysis also illustrates the power of a modelling approach in exploring and understanding plant physiology in cropping systems. 

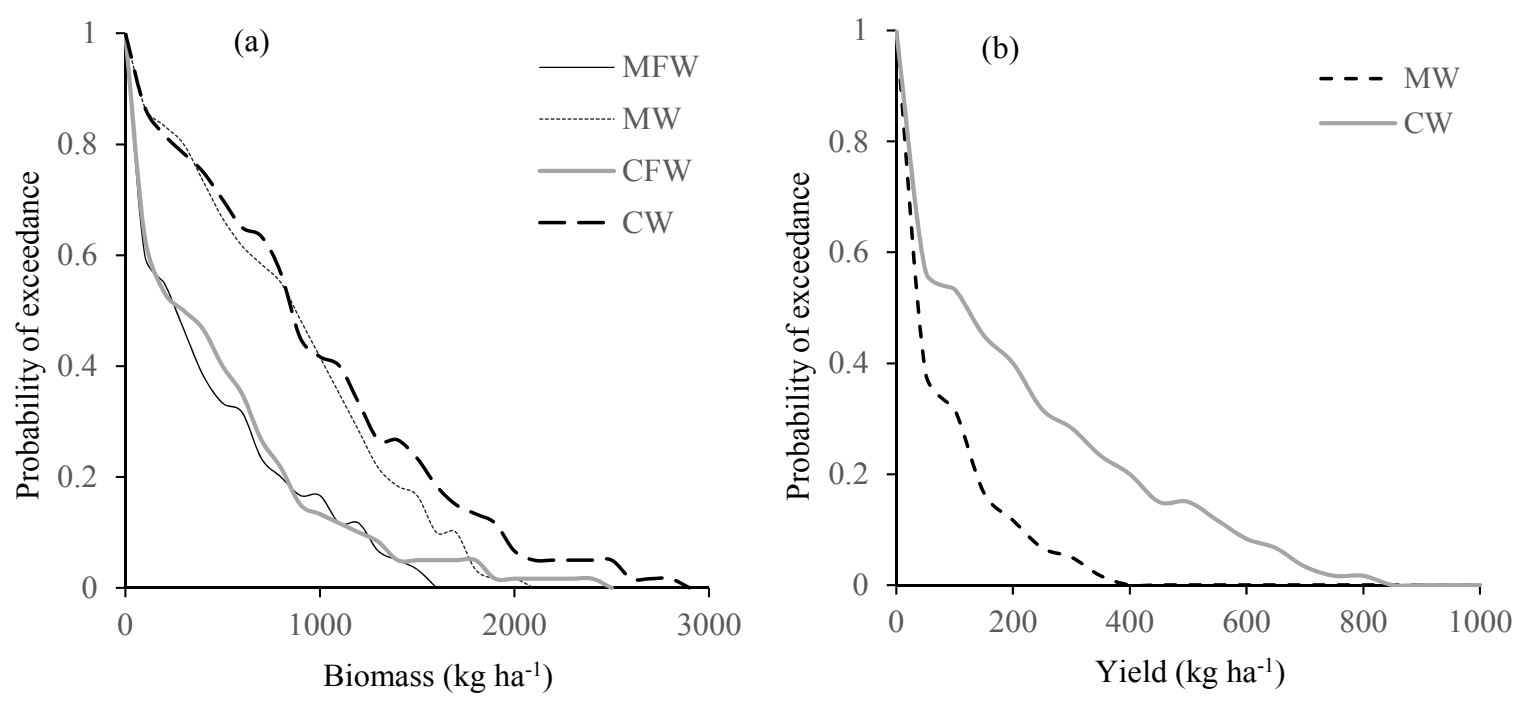

Figure 2. (a) Probability distribution of simulated biomass in a millet forage-wheat system (MFW), milletwheat system (MW), cowpea forage-wheat system (CFW) and cowpea-wheat system (CW); (b) Probability distribution of simulated summer crop yield in a MW system and CW system.

\subsection{Impact of summer crops on wheat yield}

Due to the small amount of millet growth over summer in both MFW and MW systems (Fig. 1), which did not significantly reduce stored soil moisture at wheat sowing time (data not shown), wheat grains yield after millet (MFW and MW) was not markedly affected (Fig. 3). On average it was slightly reduced (3-4\%) compared with that grown after summer fallow (Fig. 4). In contrast, when summer fallow was replaced by cowpea, the following wheat crop benefited. Wheat grain yield was increased by $9 \%$ in a CFW system and $16 \%$ in a $\mathrm{CW}$ system, thanks to contribution of biological nitrogen fixation $\left(5-6 \mathrm{~kg} \mathrm{~N} \mathrm{ha}{ }^{-1}\right.$ fixed by aboveground biomass). Despite summer rainfall was limited, summer cowpea cropping was simulated to add value to the farming system by replacing summer fallow, indicating that adopting a tactical summer crop option might result in more wheat production as compared to continuous summer fallow. However the system needs further evaluation by including economic and environmental aspects, which is a research project planned to undertake.

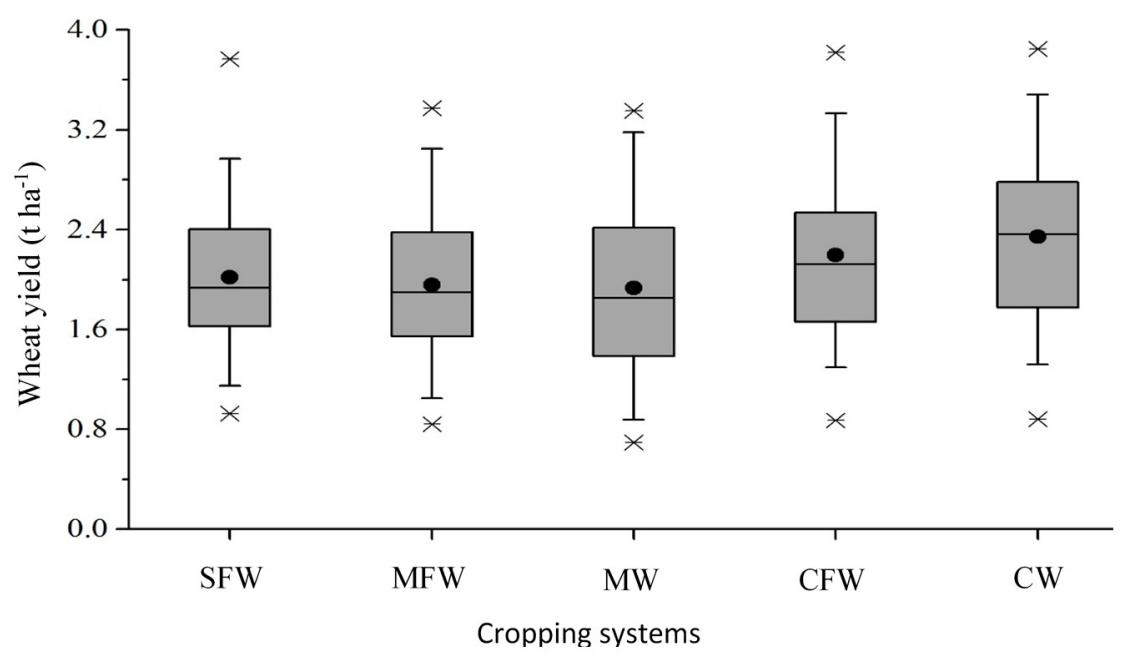

Figure 3. Simulated distribution of wheat yield under different cropping systems.

(Abbreviations provided in Sections 2.3 and 2.4). 


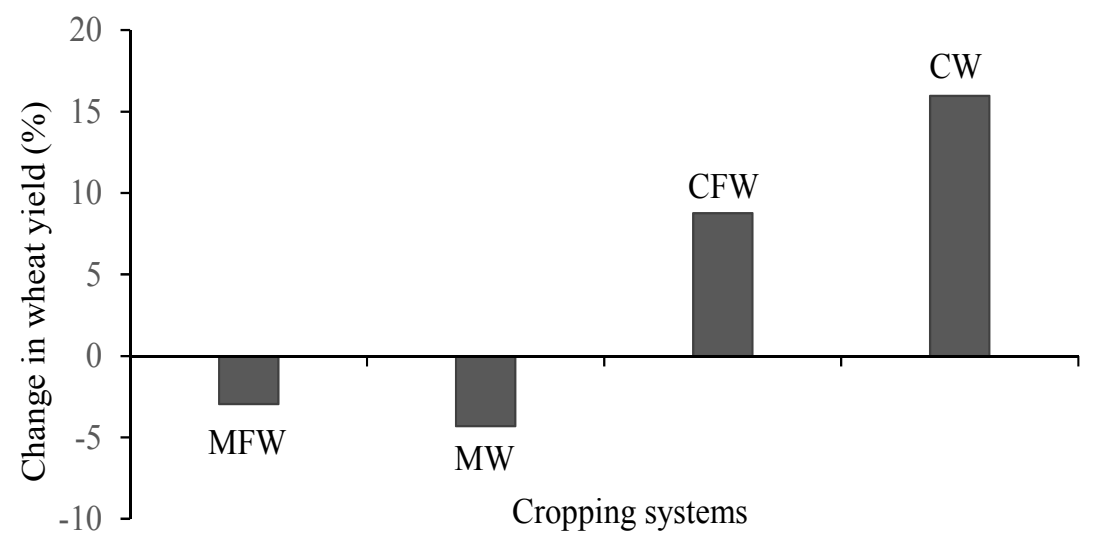

Figure 4. Change in wheat yield (\%) following various summer crops compared to a summer fallow-wheat system. (Abbreviations provided in Sections 2.3 and 2.4).

\section{CONCLUSION}

This study has quantified levels of production risk of summer crops (millet and cowpea) and their effects on a following wheat crop by using the APSIM model to incorporate summer crops into cropping systems in the central wheatbelt of WA. The amount of summer rainfall (plus the stored soil moisture available) at the study location was predicted to support biomass production of $0.85 \mathrm{t} \mathrm{ha}^{-1}$ (ranging from 0 to $2.00 \mathrm{t} / \mathrm{ha}$ ) for the millet cultivar considered and $0.96 \mathrm{t} \mathrm{ha}^{-1}$ (ranging from 0 to $2.89 \mathrm{t} / \mathrm{ha}$ ) for the cowpea. In $20 \%$ of seasons, when it rained, millet could produce $0.14-0.36 \mathrm{t} \mathrm{ha}^{-1}$ of grain yield and cowpea produced $0.40-0.83 \mathrm{t} \mathrm{ha}^{-1}$ of yield. Growing a summer crop for grain would not be desirable in a large proportion of years. Summer millet crops slightly reduced yield of a following winter wheat (3-4\%). By comparison wheat yield grown after summer cowpea was increased by $9-16 \%$, as a result of the reserves of soil mineral nitrogen increased by cowpea. Tactical crop strategies for summer crops, instead of summer fallow, could add value to the farming system. Increased confidence has been gained in the use of modelling approach in exploring crop performance in various cropping systems.

\section{ACKNOWLEDGMENTS}

We thank the Grains Research and Development Corporation for funding this research under project CSA 00029 "Break Crops Sequences". We also gratefully acknowledge the financial support of the Australian Government Department of Agriculture, Carbon Farming Futures - Action on the Ground Program.

\section{REFERENCES}

Asseng S., Keating B.A., Fillery I.R.P., Gregory P.J., Bowden J.W., Turner N.C., and Abrecht D.G. (1998). Performance of the APSIM-wheat model in Western Australia. Field Crops Res. 57(2), 163-179.

Asseng S., and Pannell D.J. (2013). Adapting dryland agriculture to climate change: farming implications and research and development needs in Western Australia. Climatic Change 118, 167-181.

Asseng S., van Keulen H., and Stol W. (2000). Performance and application of the APSIM-Nwheat model in the Netherlands. Euro. J. Agron. 12, 37-54. 
Chen et al., Model-based explorations to assess climate risk to summer crop production...

Halilou O., Hamidou F., Taya B., Mahamane S., and Vadez V. (2015). Water use, transpiration efficiency and yield in cowpea (Vignaunguiculata (L.) Walp) and peanut (Arachishypogaea L.) across water regimes. Crop and Pasture Sci 66, 715-728.

Holzworth D.P., Huth N.I., deVoil P.G., Zurcher E.J., Herrmann N.I., McLean G., Chenu K., van Oosterom E., Snow V.O., Murphy C., Moore A.D., Brown H.E., Whish J.P.M., Verrall S., Fainges J., L.W., B., Peake A.S., Poulton P.L., Hochman Z., Thorburn P.J., Gaydon D.S., Dalgliesh N.P., Rodriguez D., Cox, H., Chapman S., Doherty A., Teixeira E., Sharp J., Cichota R., Vogeler I., Li, F.Y., Wang E., Hammer G.L., Robertson M.J., Dimes J., Carberry P.S., Hargreaves J.N.G., MacLeod N., McDonald C., Harsdorf J., Wedgwood S., Keating B.A., 2014. APSIM-evolution towards a new generation of agricultural systems simulation. Environ. Model. Softw. 62, 327-350.

Jeffrey S.J., Carter J.O., Moodie K.B., and Beswick A.R. (2001). Using spatial interpolation to construct a comprehensive archive of Australian climate data. Environ. Model. Softw. 16(4), 309-330.

Robertson M.J., Gaydon D., Hall D.J.M., Hills A., and Penny S. (2005). Production risks and water use benefits of summer crop production on the south coast of Western Australia. Aust. J. Agric. Res. 56, 597612 .

Wang E., Cresswell H., Yu Q., Verburg K., 2008. Summer forage cropping as an effective way to control deep drainage in south-eastern Australia-a simulation study. Agric. Ecosyst. Environ. 125(1), 127-136. 